\title{
O cotidiano visto através das notícias e crônicas
}

Carolina Fernandes*

Resumo: O presente relato de experiência apresenta a prática pedagógica desenvolvida em estágio de Língua Portuguesa, utilizando os gêneros discursivos notícias e crônicas como motivadores tanto da leitura como da escrita. A escolha desses gêneros se deve aos seguintes aspectos: são textos curtos, por isso de fácil manuseio em aula, podem ser encontrados em jornais e revistas, assim, sendo de fácil acesso aos alunos, e, ainda, abordam assuntos do cotidiano, possibilitando que os alunos identifiquem-se com o texto, queiram interpretá-lo e refletir sobre sua realidade. Na prática, percebemos que os alunos sentiram-se estimulados a ler, interpretar e escrever textos nesses dois gêneros, o que possibilitou também a reflexão sobre a realidade que vivem, o cotidiano do jovem, seus desafios e suas impressões sobre o mundo e as relações humanas.

Palavras-chave: Língua Portuguesa; Gêneros Discursivos; Notícias; Crônicas.

Abstract: This report presents the experience of teaching practice developed stage of Portuguese Language, using the genres news and chronic as motivators reading as well as writing. The choice of these genres is due to the following: texts are short, so easy to use in the classroom, can be found in newspapers and magazines, thus being easily accessible to students, and also address issues of everyday life, enabling students identify with the text and

* Professora do curso de Letras da UNIPAMPA, doutoranda em Estudos da Linguagem pela UFRGS e mestre pela mesma Universidade. Licenciada em Letras - Português/ Francês e Respectivas Literaturas pela UFSM. E-mail: carolfernandes@unipampa. edu.br. 
want to interpret it and reflect on their reality. In practice, we realize that students felt encouraged to read, interpret and write texts in these two genres, which also allowed reflection on the reality we live, daily life of the young, their challenges and their impressions of the world and relationships human.

Keywords: Portuguese Language, Discourse Genres; News; Chronicles.

\section{Introdução}

Este trabalho tem como propósito relatar as experiências obtidas no Estágio III de Língua Portuguesa, componente curricular do Curso de Letras da Universidade Federal do Pampa.

O projeto aplicado foi desenvolvido a partir de horas de observação e aplicação de atividade diagnóstica em uma turma de primeiro ano do ensino médio noturno, em que se constatou a falta de contato dos alunos com as leituras, o que consequentemente, contribui com as dificuldades em relação à produção escrita nas aulas de Língua Portuguesa.

Com o intuito de despertar o interesse pela leitura e, consequentemente, impulsioná-los para a produção de textos, optamos pelo trabalho com os gêneros discursivos, notícia e crônica, a fim de que percebessem a especificidade desses gêneros em abordar temas extraídos do cotidiano e, por isso, podermos encontrá-los facilmente em jornais ou revistas.

\section{Caracterização da Escola}

O trabalho foi realizado na Escola Estadual de Ensino Médio Silveira Martins, localizada no centro da cidade de Bagé, RS. A escola atende alunos da educação básica ao ensino médio.

A escola mostrou-se bastante receptiva ao nosso trabalho. A realização do estágio de observação e prática foi desenvolvida 
no período compreendido entre agosto e novembro de 2012, na turma 311.

Os alunos de modo geral eram moradores de bairros afastados do centro, com idades entre quinze e dezoito anos. $\mathrm{Na}$ sua maioria, não demonstravam interesse por leitura nas aulas de língua portuguesa, o que podemos comprovar nas horas de observação, as quais foram muito valiosas para que o trabalho de prática pudesse ser melhor planejado.

Como não tinham o hábito da leitura e da escrita, propusemos-lhes o contato com os gêneros notícia e crônica, com o intuito de despertar o interesse pelo hábito de ler e, assim, estimulá-los à produção textual. Dentre os fatores que nos levaram a utilizar esses gêneros, podemos destacar que são textos curtos e fazem parte do cotidiano, abordando assuntos por que os alunos se interessam.

\section{Fundamentação teórica}

Como pressuposto teórico, partimos de Bakhtin, que, ao tratar sobre os gêneros do discurso, afirma que as atividades humanas estão intimamente ligadas aos atos de comunicação e à linguagem. Portanto "[...] a riqueza e a diversidade dos gêneros do discurso são infinitas porque são inesgotáveis as possibilidades da multiforme atividade humana e porque em cada campo dessa atividade é integral o repertório de gêneros do discurso" (BAKHTIN, 2003, p. 262).

Buscamos desenvolver, em nosso planejamento didático, um trabalho voltado para o estudo e para compreensão de textos nas aulas de Língua Portuguesa, no ensino médio. Para tanto, recorremos aos Parâmetros Curriculares Nacionais que constituem importante documento para auxiliar a prática docente. De acordo com os PCNs, "[...] o aluno deve ser considerado como produtor de textos, aquele que pode ser entendido pelos textos que produz e que o constituem como ser humano.” (PCN, 2000, p. 18). 
Sendo assim, torna-se imprescindível que profissionais que já atuam e também professores em formação tenham conhecimento dos PCNs e que se utilizem dele como instrumento de apoio e também como recurso que promova a reflexão sobre a prática docente.

Com base em tal afirmativa, compreendemos que o ensino de Língua Portuguesa deve visar à formação de alunos críticos, que sejam capazes de perceber a importância e funcionalidade de estudarem determinados conteúdos na escola.

Nesse caminho de busca por uma educação de qualidade, é fundamental que seja instigado nos alunos o interesse pela leitura, de maneira que percebam sua necessidade, não somente na escola, e sim em qualquer momento de suas vidas. Para Marisa Lajolo

Ler não é decifrar, como num jogo de adivinhações, o sentido de um texto. É a partir do texto, ser capaz de atribuir-lhe significado, conseguir relacioná-lo a todos os outros textos significativos para cada um, reconhecer nele o tipo de leitura que o autor pretendia e, dono da própria vontade, entregar-se a essa leitura, ou rebelar-se contra ela, propondo outra não prevista. (LAJOLO, 1982, p. 59)

Percebemos que muitas vezes os professores não demonstram interesse nas produçôes dos alunos, o que ocorre simplesmente é que "[...] se opacifica o texto, pois não importa com que intenções se trabalhou com a linguagem; importam, na leitura, os esmiuçamentos dos recursos, nada mais.” (GERALDI, 1996, p. 53).

Esse posicionamento reflete na desmotivação do adolescente no processo de produção textual, sendo que, se o professor demonstrasse interesse pelas atividades do aluno, se quisesse saber um pouco mais da sua realidade, a escola se tornaria um ambiente bem mais produtivo e agradável.

Para o planejamento de nossa sequência didática, foi necessário levarmos em consideração a primeira produção, pois "[...] no momento da produção inicial, os alunos tentam elaborar um primeiro texto oral ou escrito e, assim, revelam para si mesmos e para o professor as representaçóes que têm dessa atividade." 
(DOLZ; NOVERRAZ; SCHNEUWLY, 2004, p. 101). Com base nisso, o professor pode desenvolver um trabalho que objetive a análise linguística, planejando aulas que contemplem

[... a linguagem como atividade discursiva, o texto como unidade de ensino e a noção de gramática como relativa ao conhecimento que o falante tem de sua linguagem, as atividades curriculares em Língua Portuguesa correspondem, principalmente, a atividades discursivas: uma prática constante de escuta de textos orais e leitura de textos escritos e de produção de textos orais e escritos, que devem permitir, por meio da análise e reflexão sobre os múltiplos aspectos envolvidos, a expansão e construção de instrumentos que permitam ao aluno, progressivamente, ampliar sua competência discursiva (PCN, 1998).

Dessa forma as aulas de Língua Portuguesa assumem um papel desafiador e de extrema importância tanto para professores quanto para alunos. Sendo assim, os trabalhos de leitura e escrita são valorizados, objetivando-se a análise linguística e reflexiva, e consequentemente impulsionando os estudantes para a produção textual.

\section{Descrição da experiência}

O projeto de ensino aplicado foi desenvolvido através de uma sequência didática dividida em dez etapas.

Primeiramente, os alunos fizeram a leitura da crônica Não te escuto (Martha Medeiros), extraída do jornal Zero Hora, em que refletiram sobre o tema abordado, por meio de questionamentos orais e também por escrito. Tal estudo conduziu-os à reflexão de que a autora poderia ter escolhido o assunto do texto através de um fato colhido no noticiário.

Dando prosseguimento ao trabalho, foi pedido que lessem a seguinte notícia Suposto Ciclone deixa a cidade de Bagé em alerta, extraída do jornal Minuano. A partir de sua leitura, os alunos expressaram suas impressões acerca do texto através de questôes interpretativas, tais como: Qual fato foi noticiado? Quem são os 
envolvidos? Qual a região abrangida? Após, estudamos as características e como se estrutura o gênero notícia, sendo possível relacioná-las com o texto lido.

Foram disponibilizadas em aula várias imagens, retiradas de notícias de jornais. A partir dessas imagens, cada aluno produziu uma notícia em que deveriam contemplar as características estudadas.

Fizemos também a leitura de outras notícias em aula, bem como a observação de um jornal impresso para que visualizassem como se constitui a distribuição e organização dos textos em um jornal.

Seguindo com o trabalho, os alunos assistiram a dois pequenos vídeos sobre notícias televisivas (Jornal Hoje e Nacional, ambos da Rede Globo), tais vídeos abordavam os temas internet e reciclagem, respectivamente. A partir dos vídeos, os alunos responderam a algumas questões interpretativas e refletiram que, mesmo em um jornal televisivo, o jornalista produz um texto escrito antes de sua apresentação ao vivo, devendo seguir a linguagem padrão da língua e a estrutura do gênero.

As notícias produzidas pelos alunos foram devolvidas a eles com algumas orientações, as quais tinham por objetivo ajudá-los a melhorar a estrutura do texto, bem como clareza, organização das ideias e correções ortográficas. Dessa forma, sendo enfatizada a importância do trabalho de reescrita.

Partimos, então, para a análise da crônica Aprenda a chamar a polícia, de Luiz Fernando Veríssimo. A leitura foi bastante significativa, pois abordava um assunto de interesse dos alunos, $\mathrm{O}$ que desencadeou uma boa participação às questões interpretativas do texto. O tema fez com que quisessem manifestar situações vividas por eles nos bairros onde residem.

Fizemos o estudo das características do gênero relacionando-as com a crônica. Como as crônicas compreendem textos leves e curtos, foram disponibilizadas na sala cinco crônicas produzidas por alunos do primeiro ano do ensino médio, participantes da Olimpíada de Língua Portuguesa. Foi pedido que se reunissem 
em pequenos grupos para a leitura, sendo cada grupo responsável por um texto. Ao final, compartilharam com o restante da turma o tema abordado, bem como suas opiniões acerca da leitura.

Dando continuidade ao projeto, cada aluno foi instigado a também produzir uma crônica, visto que se sentiram motivados a escrever como os alunos da Olimpíada de Língua Portuguesa.

Do mesmo modo que reescreveram as notícias, tiveram a mesma oportunidade com as crônicas a fim de melhorar os textos produzidos.

\section{Avaliação dos resultados}

Com base no trabalho realizado, percebemos a relevância da escolha dos gêneros estudados, o que possibilitou a motivação e interação entre os alunos na participação nas atividades propostas. Dessa forma, as questóes interpretativas propiciaram a compreensão dos textos desde a primeira impressão pessoal acerca do texto lido até as características próprias dos gêneros, bem como estrutura e intençôes com que se lê uma notícia ou crônica.

\section{Considerações finais}

Confirmamos que as horas de observação e aplicação de atividade diagnóstica foram valiosas para o planejamento do projeto de ensino, o que proporcionou que refletíssemos sobre que textos explorar nas aulas.

O estudo dos gêneros notícia e crônica revelou-se de extrema relevância no trabalho desenvolvido. Constatou-se que tais gêneros, por abordarem os assuntos do cotidiano, possibilitaram uma importante participação dos alunos nas atividades propostas. 
Entendemos que o ambiente escolar, em especial nas aulas de Língua Portuguesa, torna-se mais agradável e atrativo quando os alunos identificam-se com os temas abordados.

\section{Referências}

BAKHTIN, Mikhail. Os gêneros do discurso. In: . Estética da criação verbal. 4. ed. São Paulo: Martins Fontes, 2003. p. 277- 326.

BRASIL. Ministério da Educação. Secretaria de Educação Fundamental. Parâmetros Curriculares Nacionais. Língua Portuguesa. Brasília: MEC/ SEF, 2000.

DOLZ, Joaquim; NOVERRAZ, Michele; SCHNEUWLY, Bernard. Gêneros orais e escritos na escola. Campinas: Mercado das Letras, 2004.

GERALDI, João Wanderley. O professor como leitor do texto do aluno. In: MARTINS, Maria Helena. (Org.). Questões de linguagem. 5. ed. São Paulo: Contexto, 1996. p.47-53.

LAJOLO, Marisa. Do mundo da leitura para a leitura do mundo. São Paulo: Ática, 1993. 